\title{
Highly Pathogenic Avian Influenza A(H5N8) Virus, Cameroon, 2017
}

\author{
Abel Wade, Simon Dickmu Jumbo, \\ Bianca Zecchin, Alice Fusaro, Taiga Taiga, \\ Alice Bianco, Poueme N. Rodrigue, \\ Angela Salomoni, Jean Marc Feussom Kameni, \\ Gianpiero Zamperin, Robert Nenkam, \\ Yacouba Foupouapouognigni, \\ Souley Abdoulkadiri, Yaya Aboubakar, \\ Lidewij Wiersma, Giovanni Cattoli, Isabella Monne
}

Highly pathogenic avian influenza $A(H 5 N 8)$ viruses of clade 2.3.4.4 spread into West Africa in late 2016 during the autumn bird migration. Genetic characterization of the complete genome of these viruses detected in wild and domestic birds in Cameroon in January 2017 demonstrated the occurrence of multiple virus introductions.

Since the first detection in China in 1996, highly patho$\checkmark$ genic avian influenza (HPAI) viruses of the $\mathrm{H} 5$ subtype descendent of the H5N1 virus A/goose/Guangdong/1/1996 (Gs/GD/96) have evolved into multiple genetic clades $(1,2)$ that have been threatening poultry worldwide. Since 2010, clade 2.3.4 has demonstrated an unusual propensity to replace its N1 subtype and acquire different neuraminidase (NA) genes from unrelated avian influenza viruses through reassortment, which has resulted in the emergence of new viral subtypes within the Gs/GD/96 H5 lineage (e.g., N2, N5, N6, N8). In late spring 2016, reassortant HPAI A(H5N8) clade 2.3.4.4 (group B) virus was detected in migratory wild birds in Qinghai Lake, China (3), and in the salt lake system of Uvs Nuur, on the border between Mongolia and the Russian Federation (4). Since then, this newly emerged virus has caused multiple outbreaks of the disease in poultry and wild birds across Europe, Asia, and the Middle

Author affiliations: Laboratoire National Veterinaire, Yaoundé and Garoua, Cameroon (A. Wade, S. Dickmu Jumbo, P.N. Rodrigue, R. Nenkam, Y. Foupouapouognigni, S. Abdoulkadiri, Y. Aboubakar); Ministry of Livestock, Fisheries and Animal Industries, Yaoundé (A. Wade, T. Taiga, J.M. Feussom Kameni); Istituto Zooprofilattico Sperimentale delle Venezie, Padova, Italy (B. Zecchin, A. Fusaro, A. Bianco, A. Salomoni, G. Zamperin, I. Monne); Food and Agriculture Organization of the United Nations, Rome, Italy (L. Wiersma); Animal Production and Health Laboratory, Seibersdorf, Austria (G. Cattoli)

DOI: https://doi.org/10.3201/eid2407.172120
East and has extended not only to countries in northern, central, and western Africa, as did the previous Gs/GD/96 H5 lineage outbreaks, but also to the eastern and southern parts of Africa (5). We investigated the epidemiology of the outbreaks in early 2017 of HPAI H5N8 virus in domestic and wild birds in Cameroon and determined the possible origin of this virus through whole-genome analyses.

\section{The Study}

On January 2, 2017, high death rates were reported in Indian peafowl (Pavo cristatus) in a backyard exotic poultry farm located in the town of Makilingaye (Tokombéré district of Mayo-Sava division), a village neighboring Nigeria in the far-north region of Cameroon. Samples were collected by the Cameroon Epidemio-Surveillance Network (Reseau d'Epidemio-Surveillance au Cameroun [RESCAM]) of the Ministry of Livestock, Fisheries and Animal Industries and were sent to the National Veterinary Laboratory (LANAVET) in Garoua, where the H5N8 subtype was diagnosed. Almost all the peafowl (103/107) died within $\approx 2$ weeks. Death in chickens (Gallus gallus domesticus, 24/24) housed in the same compound was delayed and appeared 5 days later than in peafowl. Following the laboratory confirmation of the first outbreak, the Cameroon government, through the Ministry of Livestock, Fisheries, and Animal Industries, implemented prompt and strong control measures to stop the spread of the virus and reduce the risk of human infections. Stamping out was deployed together with movement restrictions and virological surveillance; disinfection of premises and contact materials was intensified. The RESCAM team conducted a routine avian influenza survey in the Maroua, Yagoua, and Guidiguis central poultry markets in the far-north region. All the samples were analyzed at LANAVET Garoua and Annex Yaounde; H5N8 virus was detected in 5 birds ( 1 pigeon, 1 chicken, 2 guinea fowls, and 1 duck) out of 122 birds.

We sequenced the hemagglutinin (HA) and NA gene segments of the virus A/Indian peafowl/ Cameroon/17RS1661-6/2017, identified from an Indian peafowl in Makilingaye, at the Istituto Zooprofilattico Sperimentale delle Venezie in Legnaro, Italy, along with the complete genomes of 2 positive samples collected from domestic birds (chicken and duck) and the partial genome (all segments except for polymerase acidic protein [PA] and polymerase basic protein 1 [PB1]) of a sample from 
Table. Epidemiologic information of viruses characterized in study of highly pathogenic avian influenza $A(H 5 N 8)$ virus, Cameroon, January 2017*

\begin{tabular}{|c|c|c|c|}
\hline Virus & Sample type & Location & EpiFlu accession numbers for 8 gene segments \\
\hline A/chicken/Cameroon/17RS1661-1/2017 & Tracheal swab & Maroua market & $\begin{array}{c}\text { HA, MG650619; MP, MG650622; NA, MG650626; NP, } \\
\text { MG650630; NS, MG650632; PA, MG650635; PB1, } \\
\text { MG650638; PB2, MG650641 }\end{array}$ \\
\hline A/duck/Cameroon/17RS1661-3/2017 & Tracheal swab & Yagoua market & $\begin{array}{c}\text { HA, MG650620; MP, MG650623; NA, MG650627; } \\
\text { NP,MG650629; NS, MG650633; PA, MG650636; PB1, } \\
\text { MG650637; PB2, MG650639 }\end{array}$ \\
\hline A/pigeon/Cameroon/17RS1661-4/2017 & Cloacal swab & Maroua market & $\begin{array}{l}\text { HA, MG650621; MP, MG650624; NA, MG650628; NP, } \\
\text { MG650631; NS, MG650634; PA, NR; PB1, na; PB2, } \\
\text { MG650640 }\end{array}$ \\
\hline $\begin{array}{l}\text { A/Indian peafowl/Cameroon/17RS1661- } \\
6 / 2017\end{array}$ & Tracheal swab & Makilingaye & $\begin{array}{c}\text { HA, MG650619; MP, NR; NA, MG650626; NP, NR; NS, } \\
\text { NR; PA, NR; PB1, NR; PB2, NR }\end{array}$ \\
\hline
\end{tabular}

a wild pigeon, all identified in the Maroua and Yagoua markets (Table). A detailed description of the methods used for sequencing and genetic analyses is provided in online Technical Appendix 1 (https://wwwnc.cdc.gov/ EID/article/24/7/17-2120-Techapp1.pdf) and details on the HA gene segments used for the analysis are given in
Technical Appendix 2 (https://wwwnc.cdc.gov/EID/article/ 24/7/17-2120-Techapp2.xlsx). We submitted consensus sequences to GenBank (accession nos. MG650618-41).

Topology of the phylogenetic tree based on the HA gene segment showed that the $4 \mathrm{H} 5 \mathrm{~N} 8$ viruses detected in Cameroon in 2017 fell within genetic clade 2.3.4.4 group

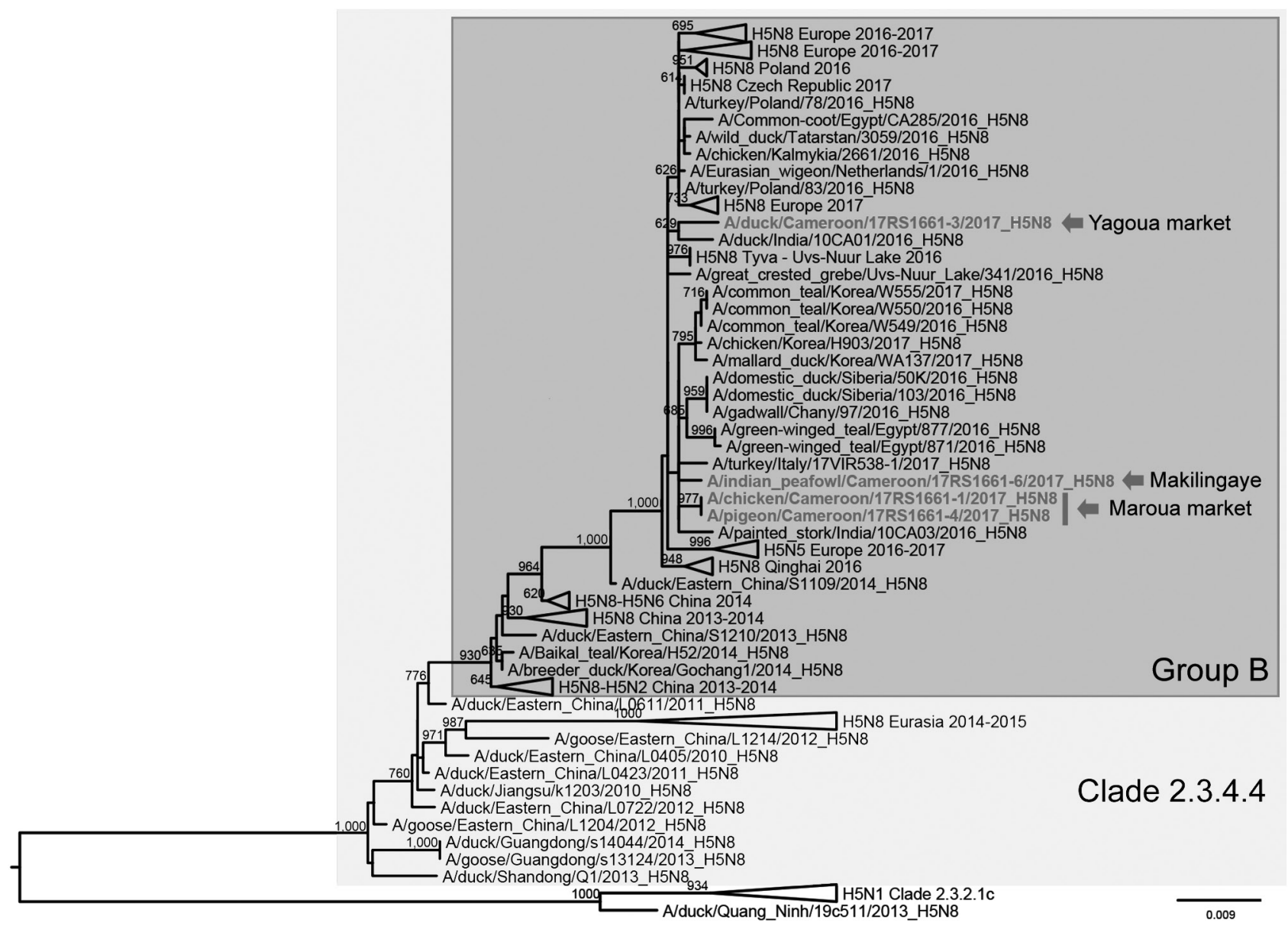

Figure. Maximum-likelihood phylogenetic tree of the HA gene of highly pathogenic avian influenza A(H5N8) virus from Cameroon (bold) and reference viruses. Arrows indicate location where Cameroon viruses were obtained. Bootstrap supports $>600 / 1,000$ are indicated next to the nodes. Scale bar indicates numbers of nucleotide substitutions per site. 
B (Figure; online Technical Appendix 1 Figure 1). The HA gene segments of the 3 viruses from Makilingaye (A/Indian peafowl/Cameroon/17RS1661-6/2017) and Maroua market clustered together; similarity ranged from $99.5 \%$ (between the viruses collected from Makilingaye and Maroua markets) to $100 \%$ (between the 2 viruses from Maroua market). These segments grouped with $\mathrm{H} 5 \mathrm{~N} 8$ viruses collected during 2016-2017 in South Korea, Egypt, Italy, Siberia, and India (similarity between $99.3 \%$ and $99.6 \%$ ). However, the virus A/duck/Cameroon/17RS1661-3/2017 identified in Yagoua market clustered separately and showed the highest similarity (99.3\%) to a virus from India (A/duck/India/10CA01/2016) (Figure).

We confirmed the different clustering of the viruses collected from distinct markets in Cameroon by the analyses of the other gene segments, which suggests the occurrence of $\geq 2$ distinct viral introductions in the country. Specifically, sequences of the 2 viruses from Maroua market were identical for all the available gene segments (Table) and clustered with viruses collected in Asia, Europe, and Egypt (online Technical Appendix 1 Figures 2-8). On the other hand, the virus A/duck/Cameroon/17RS1661-3/2017 grouped with the A/duck/India/10CA01/2016 virus (similarity 94.3-99.9\%), except for the nucleoprotein (NP) gene, where it showed the highest identity (99.3\%) with a virus collected in 2016 in the Russian Federation (Uvs Nuur Lake). The lack of genetic information on other H5N8 viruses detected in Africa makes it impossible to pinpoint how these viruses entered Cameroon and spread, nor is it feasible to determine where the 2 introductions occurred. The time to the most recent common ancestor estimated for the HA gene (online Technical Appendix 1) suggested that 2 introductions into Africa may have occurred almost simultaneously during March-December 2016 (online Technical Appendix 1 Figure 9). However, analyses of the amino acid sequences show that A/duck/Cameroon/17RS1661-3/2017 possesses the N319K mutation in the NP protein, which has been reported to enhance polymerase activity and stimulate vRNA synthesis in mammalian cells (6). In addition, A/ chicken/Cameroon/17RS1661-1/2017 contains the V100A mutation in the PA protein, which is an amino acid signature typical of human influenza viruses (7).

\section{Conclusions}

Nigeria was the first country in West Africa to report the presence of the HPAI H5N8 virus in November $2016(8,9)$. Less than 2 months later, in January 2017, the virus was detected in the far-north region of Cameroon in Makilingaye, close to the Nigerian border. Considering the extensive and porous frontier between Cameroon and Nigeria, trade and movement of poultry might have played a key role in the spread of the virus. However, the involvement of wild birds cannot be excluded. The region contains several wetlands
(Domayo River, Mayo Kani River, and Maga Lake) where different wild birds congregate, in particular during the dry season (December-April), when the virus was first detected. The almost simultaneous detection (early January 2017) of the H5N8 virus in poultry and wild birds in distant locations in Africa, such as Tunisia and Uganda, suggests that the role of wild birds in the introduction and/or dissemination of the virus in the region should not be overlooked. Of note, the first outbreak caused by the Gs/GD/96 H5 lineage in Cameroon, in 2006, also occurred in the far-north region of Cameroon at about the same time. This finding might suggest a common pathway for introduction of the virus into this area and highlights the need to improve surveillance in this region.

Although the epidemiologic and genetic data are insufficient to establish definite pathways and time of introduction of H5N8 virus into West Africa, this study demonstrates that $\geq 2$ distinct $\mathrm{H} 5 \mathrm{~N} 8$ viruses entered Cameroon. This finding, together with the evidence that this event represents the third incursion of a Gs/GD/96-lineage H5 HPAI virus into Cameroon, again underlines the need to perform avian influenza surveillance on an ongoing basis for rapid identification and response to outbreaks in this area.

\section{Acknowledgments}

We thank the RESCAM team for efficient disease surveillance in the field, all the administrators and traditional leaders involved in field decision making, the forces of order who assisted during stamping out, the Food and Agriculture Organization of the United Nations (UN-FAO) country team, and the International Atomic Energy Agency for their support. We also acknowledge the authors and the originating and submitting laboratories of the sequences from the GISAID EpiFlu database, on which this research is based in part (online Technical Appendix 2).

The laboratory analyses were supported by UN-FAO with funding from the US Agency for International Development (USAID) under the projects OSRO/GLO/501/USA, titled "Emergency Assistance for Prevention and Control of H5N1 HPAI in West and Central Africa," and OSRO/GLO/507/USA, titled "Supporting the Global Health Security Agenda (GHSA) to Address Zoonotic Disease and Animal Health in Africa." The content of this article is the responsibility of the author(s) and does not necessarily reflect the views of UN-FAO, USAID, or the US Government. This work was also supported by the International Atomic Energy Agency Peaceful Uses Initiatives project, funded by the Government of Japan.

\section{About the Author}

Dr. Wade is a molecular microbiologist and veterinarian at the National Veterinary Laboratory in Yaounde, Cameroon. His research interest is the molecular diagnosis and epidemiology of animal infectious diseases, including zoonoses. 


\section{References}

1. World Health Organization/World Organisation for Animal Health/ Food and Agriculture Organization (WHO/OIE/FAO) H5N1 Evolution Working Group. Toward a unified nomenclature system for highly pathogenic avian influenza virus (H5N1). Emerg Infect Dis. 2008;14:e1. http://dx.doi.org/10.3201/eid1407.071681

2. World Health Organization/World Organisation for Animal Health/ Food and Agriculture Organization (WHO/OIE/FAO) H5N1 Evolution Working Group. Revised and updated nomenclature for highly pathogenic avian influenza A (H5N1) viruses. Influenza Other Respir Viruses. 2014;8:384-8. http://dx.doi.org/10.1111/ irv. 12230

3. Li M, Liu H, Bi Y, Sun J, Wong G, Liu D, et al. Highly pathogenic avian influenza $\mathrm{A}(\mathrm{H} 5 \mathrm{~N} 8)$ virus in wild migratory birds, Qinghai Lake, China. Emerg Infect Dis. 2017;23:637-41. http://dx.doi.org/ 10.3201/eid2304.161866

4. Lee DH, Sharshov K, Swayne DE, Kurskaya O, Sobolev I, Kabilov M, et al. Novel reassortant clade 2.3.4.4 avian influenza $\mathrm{A}(\mathrm{H} 5 \mathrm{~N} 8)$ virus in wild aquatic birds, Russia, 2016. Emerg Infect Dis. 2017;23:359-60. http://dx.doi.org/10.3201/ eid2302.161252

5. World Organisation for Animal Health. Immediate notifications and follow-up reports of highly pathogenic avian influenza (types
H5 and H7). 2017 [cited 2017 Dec 19]. http://www.oie.int/en/ animal-health-in-the-world/update-on-avian-influenza/2017.

6. Gabriel G, Abram M, Keiner B, Wagner R, Klenk HD, Stech J. Differential polymerase activity in avian and mammalian cells determines host range of influenza virus. J Virol. 2007;81:9601-4. http://dx.doi.org/10.1128/JVI.00666-07

7. Finkelstein DB, Mukatira S, Mehta PK, Obenauer JC, Su X, Webster RG, et al. Persistent host markers in pandemic and H5N1 influenza viruses. J Virol. 2007;81:10292-9. http://dx.doi.org/ 10.1128/JVI.00921-07

8. World Organisation for Animal Health. Immediate notifications and follow-up reports of highly pathogenic avian influenza (types H5 and H7). 2016 [cited 2017 Dec 19]. http://www.oie.int/en/ animal-health-in-the-world/update-on-avian-influenza/2016.

9. Selim AA, Erfan AM, Hagag N, Zanaty A, Samir AH, Samy M, et al. Highly pathogenic avian influenza virus (H5N8) clade 2.3.4.4 infection in migratory birds, Egypt. Emerg Infect Dis. 2017;23:1048-51. http://dx.doi.org/10.3201/eid2306.162056

Address for correspondence: Isabella Monne, Istituto Zooprofilattico Sperimentale delle Venezie, viale dell'università 10, Legnaro, Padova 35020, Italy; email: imonne@izsvenezie.it

\section{December 2015: Zoonotic Infections}

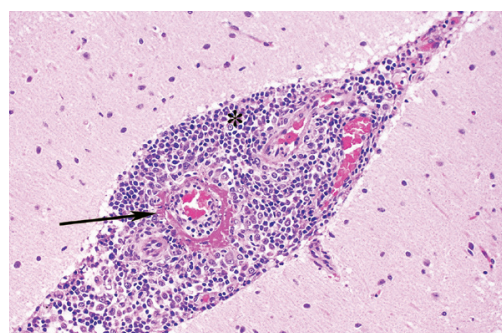

- Identifying and Reducing Remaining Stocks of Rinderpest Virus

- Opportunistic Pulmonary Bordetella hinzii Infection after Avian Exposure

- Zoonotic Leprosy in the Southeastern United States

- Infection Risk for Persons Exposed to Highly Pathogenic Avian Influenza A H5 Virus-Infected Birds, United States, December 2014-2015

- High Prevalence of Intermediate Leptospira spp. DNA in Febrile Humans from Urban and Rural Ecuador
- Biological Warfare Plan in the 17th Century-the Siege of Candia, 1648-1669

- Influenza A(H6N1) Virus in Dogs, Taiwan

- Methicillin-Resistant Staphylococcus aureus Prevalence among Captive Chimpanzees, Texas, USA, 2012

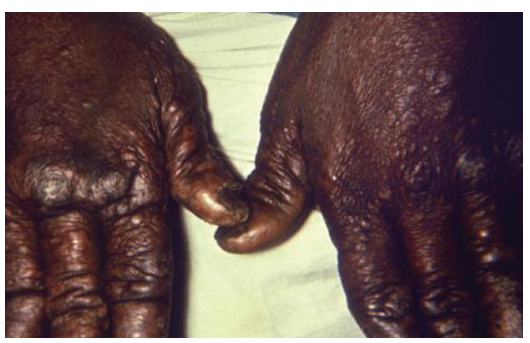

- Novel Waddlia Intracellular Bacterium in Artibeus intermedius Fruit Bats, Mexico

- Tembusu-Related Flavivirus in Ducks, Thailand

- Japanese Macaques (Macaca fuscata) as Natural Reservoir of Bartonella quintana
- Onchocerca lupi Nematode in a Cat, Europe

- Increased Number of Human Cases of Influenza Virus $\mathrm{A}(\mathrm{H} 5 \mathrm{~N} 1)$ Infection, Egypt, 2014-15

- Replication Capacity of Avian Influenza A(H9N2) Virus in Pet Birds, Chickens, and Mammals, Bangladesh

- Hendra Virus Infection in Dog, Australia, 2013

- No Evidence of Gouléako and Herbert Virus Infections in Pigs, Côte d'Ivoire and Ghana

- Aquatic Bird Bornavirus 1 in Wild Geese, Denmark

- Vectorborne Transmission of Leishmania infantum from Hounds, United States

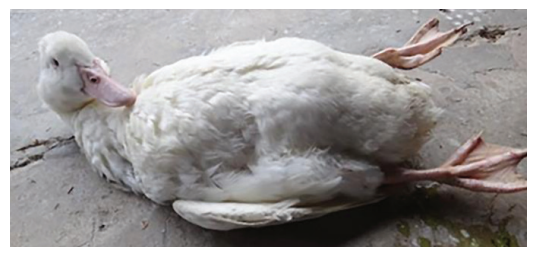

